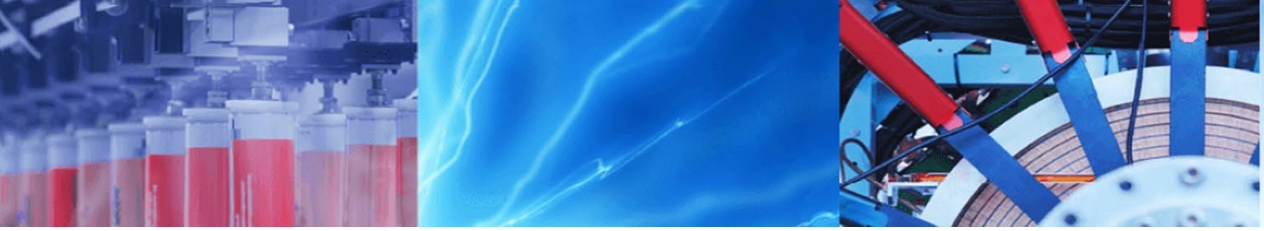

Research Article

\title{
Simultaneous effects of ethyl vinyl acetate (EVA) and glass fiber on the properties of the hot mix asphalt (HMA)
}

\author{
Omid Janmohammadi ${ }^{1} \cdot$ Ebrahim Safa $^{2} \cdot$ Mohammad Zarei $^{3} \cdot$ Ali Zarei $^{4}$
}

Received: 4 March 2020 / Accepted: 28 May 2020 / Published online: 4 June 2020

(c) Springer Nature Switzerland AG 2020

\begin{abstract}
One of the best ways to improve the asphalt mix performance is to increase the adhesion among its components using different additives. Considering the viscoelastic behavior of bitumen, adding the secondary additives as a complement can improve the properties of the asphalt mix. This study aimed to conduct a laboratory research study that evaluated the performance of asphalt mixtures prepared with ethyl vinyl acetate (EVA) modified bitumen containing different amounts of glass fibers. For this purpose, a total of 11 types of mixtures were made, and Marshall and resilient modulus tests were performed to investigate the effect of additives on specimens. The results showed that adding 5\% EVA and $0.3 \%$ glass fiber increased the Marshall Stability by about 25 and $20 \%$, respectively. It was also concluded that the simultaneous use of both additives increased Marshall Stability more than adding any of them separately. The highest Marshall Stability belongs to the sample containing 3\% of EVA and $0.3 \%$ of glass fiber, which is equal to $1210 \mathrm{~kg}$. On the other hand, the results of the resilient modulus indicated that by increasing the percentage of EVA and glass fiber separately and simultaneously at two different temperatures of 25 and $40{ }^{\circ} \mathrm{C}$, the resilient modulus of the asphalt mix was increased. However, rising temperatures reduced the resilient modulus of asphalt mix. Based on all results, $3 \mathrm{EF}$ was selected as the most optimal asphalt mix.
\end{abstract}

Keywords EVA · Glass fiber $\cdot$ Asphalt mix $\cdot$ Marshall $\cdot$ Resilient modulus

\section{Introduction}

Distress in HMA pavements reduces the durability of HMA pavements and increases road maintenance costs [39].r Researchers have evaluated improving the asphalt mix using different additives, polymers, nanomaterial, fillers, fibers, recycled materials, to name a few important ones $[1,7,16,26-29,33,34,36,37]$.

Some of these additives, in addition to their environmental benefits, improve the engineering properties and performance of the asphalt mixture $[6,11]$. Also, researchers have used various materials such as Recycled asphalt materials (RAM) to improve the technical properties of the asphalt mix. The results improved the technical properties of the asphalt mix [40].

Recent researches in the field of nanomaterial and fibers have examined the effect of these additives on asphalt mixtures. The findings show that nanomaterials affect the asphalt mix positively $[4,17,25,28,30,32]$. Also, the fibers are used to improve the dynamic and mechanical properties of the asphalt mix. Polyester fiber, carbon fiber, glass fiber, etc. are among these kinds of additives. Various studies have been conducted to investigate the effect of fiber on the asphalt mix. The results showed that the

$\triangle$ Mohammad Zarei, mohammadzarei959@yahoo.com; Omid Janmohammadi, Omidjanmohammadi@gmail.com; Ebrahim Safa, e_safa@azad.ac.ir; Ali Zarei, eng.ali.zarei69@gmail.com | 'Department of Civil Engineering, Azad University, Central Tehran Branch, Tehran 66933501, Iran. ' Department of Civil Engineering, Islamic Azad University, South Tehran Branch, Tehran 66933501, Iran. ${ }^{3}$ Department of Civil Engineering, Imam Khomeini International University, Qazvin 33780043, Iran. ${ }^{4}$ Department of Civil Engineering, Razi University, Kermanshah 342776056, Iran. 
fibers significantly improved the technical properties of the asphalt mixture [16, 19, 22, 27].

Polymers are among the useful additives for modifying the properties of bitumen and asphalt. In their research, Hafeez and Kamal [10] evaluate the effects of polymer on the asphalt and conclude that it improves the technical properties of the asphalt mix [10]. Khattak and Baladi [13] studied the effects of using polymers as modifiers and stated that polymers make the bitumen more resistant to loading and less sensitive to thermal changes. It should be noticed that while the additives may improve the technical properties of the asphalt mix, it would be impossible to use them in the asphalt if it is not economically justifiable. Considering the researches done in this field, two types of additives, including ethyl vinyl acetate (EVA) and glass fiber, are used.

\subsection{EVA}

Ethylene vinyl acetate (EVA) polymer is compatible with most types of bitumen and has good consistency at normal temperatures for transport and mixing [23]. The bitumen modified with EVA polymer has got a higher softening point and displays more stiffness and viscosity. It does not need a higher admixture and compaction temperature. When modified bitumen is used in the surface layer of the asphalt, it increases the resistance to permanent deformation [23].

EVA is a copolymer containing the amorphous vinyl acetate and semicrystalline polyethylene, which is used to improve the properties of asphalt mix [24]. The polyethylene blocks are probably crystallized and form areas that act as knots for cross-linking. At ambient temperature, EVA polymer displays viscoelastic specifications due to the existence of crystallized areas. These areas are melted and form a liquid [23]. Saoula et al. [20] worked on the operational improvement in the asphalt mix modified by EVA and EVA-Waste. In their research, they used one type of asphalt mix and tried two ways of making it. Process $A$ makes the polymeric bitumen and the asphalt mix, and process $B$ adds polymer to the asphalt mix while making it. Marshall experiment is used to evaluate the asphalt mix. The percentages used for EVA were 3.5 and 7, and 1 to 4 for EVA-Waste. The results of this research [20] show that:

- Increasing the percentages of EVA and EVA-Waste decreases the penetration grade and thermal sensitivity of the modified mix, and increases the softening point and asphaltene percentage.

- Increasing polymer percentage improves the Marshall Stability and flow. State A (EVA) was better than state B (EVA-Waste).

\section{SN Applied Sciences}

- In both ways of making the mix, the best Marshall Stability and flow belonged to 5\% of EVA and 2\% of EVAWaste.

The results of a study showed that the temperature susceptibility of EVA-modified asphalt was lower than lowdensity polyethylene LDPE-modified asphalt [12]. Also, at a content of about 9\%, EVA-modified asphalt shows a lower temperature susceptibility than SBS-modified asphalt [14]. In general, EVA copolymers (containing approximately $18-28 \%$ vinyl acetate content) do not change the rheological properties of asphalt compared to SBS copolymers [31]. Behnood and Gharehveran [8] showed that the appearance of a continuous polymer network occurs in the presence of a 5-6\% polymer. According to studies, the addition of EVA has improved the properties of the asphalt mixture at low percentages. As a result, we used EVA additive to improve the mechanical and dynamic properties of the asphalt mix.

\subsection{Glass fiber}

Using fiber in the asphalt prevents the spread of cracks and increases the life of the pavement [9]. Therefore, many researchers tend to use the fibers to arm the asphalt. Glass fiber is a type of fiber that is very useful in industry and increases the stability, fatigue life, and durability of the asphalt samples [9]. One of the features of glass fiber is that it spreads in the asphalt mix very well and controls the spread of cracks. At high temperatures, due to the viscosity of the bitumen, the tensile stress applied to the asphalt mix is not transferred to the fibers. This makes the use of fibers at high temperatures ineffectual [15].

Zarei et al. [35], evaluated the effect of lignin and glass fiber on the asphalt mix. According to the results, the use of glass fibers with a length of $12 \mathrm{~mm}$ increases the resilient modulus of asphalt mix. However, the resilient modulus of the samples containing fibers with a length of $6 \mathrm{~mm}$ decreases. Conducted researches on the simultaneous use of Diatomite and glass fiber show that they increase the resistance to rutting and fatigue compared to the control sample. Diatomite mostly influences the resistance to wheel effect (rut depth) while the glass fiber affects the fatigue. However, at low percentages, none of the additives have a significant effect on the results. Generally speaking, the asphalt samples mixed with Diatomite and glass fiber deliver better performance against fatigue [35].

Ziari et al. [42] investigated the effect of reclaimed asphalt pavement (RAP) and glass fiber on the crack resistance of HMA. Based on the results of the fracture test, the use of $0.12 \%$ glass fiber resulted in a significant improvement in the crack resistance of the asphalt mix. Also, by increasing the 
glass fibers and RAP content, the fracture resistance of HMA improved due to the increase in stiffness of the mixtures [42].

Ziari and Moniri [41] evaluated the effect of polyolefin glass fibers on the moisture sensitivity, rutting resilient modulus, fatigue, and fracture resistance of asphalt mix. The results show that the use of $0.12 \%$ polyolefin glass fiber improves the mentioned properties due to an increase in the elastic behavior and stiffness of the mixture. The resilient modulus was increased significantly when the mixture was modified with $0.12 \%$ fiber. However, the resilient modulus decreased slightly with increasing fiber percentage to $0.18 \%$. [41].

If the fibers are too long, there is a problem called balling [2]. As mentioned earlier, some fibers may produce a mass which prevents them from being well mixed with the asphalt. If the fibers are too short, they do not affect, playing the role of an expensive filler. Improving the tensile properties based on composite behavior is the main reason for the efficiency of the fibers. They may increase the strain absorption energy and postpone the process of the asphalt mix failure [35]. Considering the unique properties of the fibers in the asphalt mix, we use fibers of $12 \mathrm{~mm}$ in length to evaluate the effects of glass fibers on the mechanical and dynamic properties of the asphalt mix.

\subsection{The simultaneous effect of EVA and glass fiber on the asphalt mix}

There are a limited number of research done on the simultaneous use of two additives. Zahedi et al. and Mirbaha et al. evaluated the effects of two additives on the asphalt mix. The results showed that the two additives improve the properties of the asphalt mix [16, 25]. Zarei et al. studied the effects of lignin and glass fiber on the asphalt mix. According to their research, the effect of the two additives increases the resistance and the resilient modulus [35].

The goal of this paper is to optimize mixes with a combination of fiber and EVA. Given that the effect of the two types of additives in previous research has led to satisfactory results, the effect of ethylene-vinyl acetate (EVA) and glass fibers on the mechanical and dynamic properties of the asphalt mix was evaluated both separately and simultaneously.

\section{Materials and preparation of samples}

\subsection{Material}

The aggregates of Kermanshah Asphalt Company located in Ghazanchi were used to make the laboratory samples. Table 1 shows the ratios of the aggregates in the surface
Table 1 Mixing ratios of the aggregates

\begin{tabular}{lllll}
\hline $\begin{array}{l}\text { Aggregates proper- } \\
\text { ties }\end{array}$ & Medium sand & Tiny sand & Sand & Filler \\
\hline Particle size & $4.75-25 \mathrm{~mm}$ & $0-19 \mathrm{~mm}$ & $0-6 \mathrm{~mm}$ & Micron \\
Mixing percentage & 8 & 23 & 68 & About 1 \\
\hline
\end{tabular}

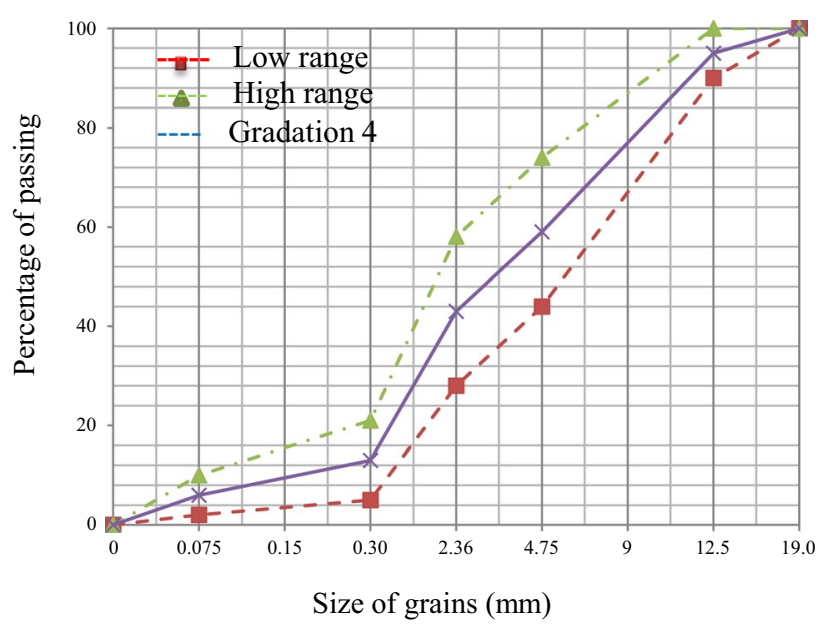

Fig. 1 Gradation graph of surface course

layer. Figure 1 shows the gradation curve obtained by mixing the weight percentages of aggregates.

The bitumen used for this study was from the Isfahan oil refinery. The properties of the bitumen are presented in Table 2.

The EVA polymer was from Alsapa Company (Hanwha brand). The polymer grade was in 1528. It was made in the form of clear Granol, which was made of almost $20 \%$ of vinyl acetate (Fig. 2).

Glass fiber has got a suitable strength and stiffness and preserves its mechanical properties in high temperatures. It has got a suitable moisture and corrosion resistance. Glass fiber is rather inexpensive. In this study, glass fibers (type A) with a length of $12 \mathrm{~mm}$ were used. These fibers were cut industrially at a length of $12 \mathrm{~mm}$. The glass fiber used in this research was produced in Boloorin-Tar Company. Figure 3 shows the properties of these fibers. Physical properties of glass fiber are presented in Table 3.

\subsection{Preparation of samples}

\subsubsection{Making bitumen modified with EVA}

In order to make the asphalt samples, first, the bitumen was mixed with different percentages of EVA polymer, and then, the asphalt samples were made using the modified bitumen. The bitumen and EVA were mixed 
Table 2 Test results on bitumen

\begin{tabular}{|c|c|c|c|c|c|}
\hline \multirow[t]{2}{*}{ Pure bitumen test } & \multicolumn{2}{|l|}{ Test result } & \multirow[t]{2}{*}{$\begin{array}{l}\text { Result base } \\
\text { on ASTM }\end{array}$} & \multicolumn{2}{|c|}{$\begin{array}{l}\text { Standard speci- } \\
\text { fications pure } \\
\text { bitumen }(60-70)\end{array}$} \\
\hline & AASHTO & ASTM & & Min & Max \\
\hline Specific gravity at $25^{\circ} \mathrm{C}$ & T228 & D70 & 1.019 & - & - \\
\hline Penetration at $25^{\circ} \mathrm{C}(100 \mathrm{~g}-5 \mathrm{~s})$ & T49 & D5 & 60 & 60 & 70 \\
\hline Softening point (ball-ring) in Celsius & T53 & D36 & 49.5 & 49 & 56 \\
\hline Ductility $(5 \mathrm{~cm} / \mathrm{dk})$ & T51 & D113 & 125 & 100 & - \\
\hline Solubility in tertiary chloride & T44 & D2042 & 99.23 & 99 & - \\
\hline Frasse breakpoint (Celsius)_UK standard IP80 & * & * & -14 & - & - \\
\hline Flash point $\left({ }^{\circ} \mathrm{C}\right)$ & T48 & D92 & 300 & 232 & - \\
\hline Kinematic viscosity at $120^{\circ} \mathrm{C}$ (CStux) & T201 & D2170 & 587 & - & - \\
\hline Kinematic viscosity at $135^{\circ} \mathrm{C}$ (CStux) & T201 & D2170 & 354 & - & - \\
\hline Kinematic viscosity at $160^{\circ} \mathrm{C}$ (CStux) & T201 & D2170 & 146 & - & - \\
\hline Thick bitumen glaze (163-5 h) & T179 & D1754 & & & \\
\hline Heat loss percentage & & & 0.8 & 0.029 & 0.8 \\
\hline Degree of penetration after heat loss tests & & & - & 39 & - \\
\hline Percentage of the degree of penetration after testing to the degree of primary $p$ & netration & & - & 63.33 & - \\
\hline The amount of stretch of bitumen after thermal loss test at $25 \mathrm{~cm}$ & & & - & +50 & - \\
\hline \multicolumn{6}{|l|}{ Bitumen thermal sensitivity } \\
\hline $\mathrm{PI}$-(in terms of degree of penetration at $25^{\circ} \mathrm{C}$ and softness point of bitumen) & & & - & -0.89 & - \\
\hline PVN-(per degree of penetration of $25 \mathrm{~cm}$ and viscosity in Cstux at $135^{\circ} \mathrm{C}$ ) & & & - & -0.943 & - \\
\hline
\end{tabular}

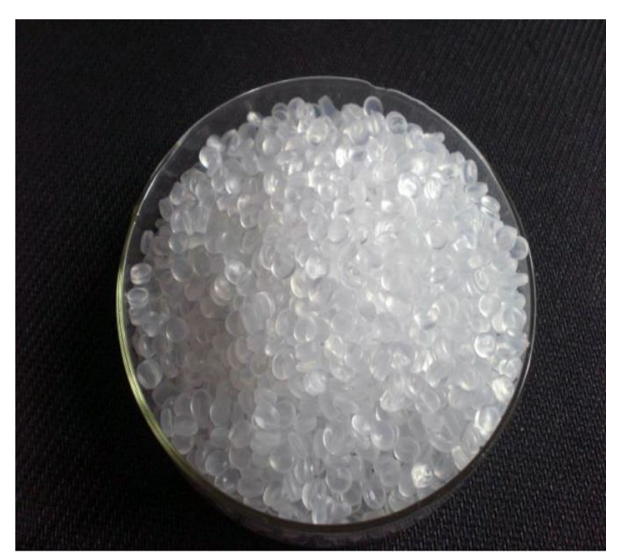

Fig. 2 A diagram of EVA

based on AASHTO-M320 and ASTM-D6373 standards. According to these standards, the bitumen was first heated up to 160 degrees centigrade. Then, the polymer was gradually added to the bitumen. The mix was stirred with the shear mixer (5000 rpm) at a stable temperature for $30 \mathrm{~min}$ to mix the bitumen and polymer in the best way possible (Fig. 4).

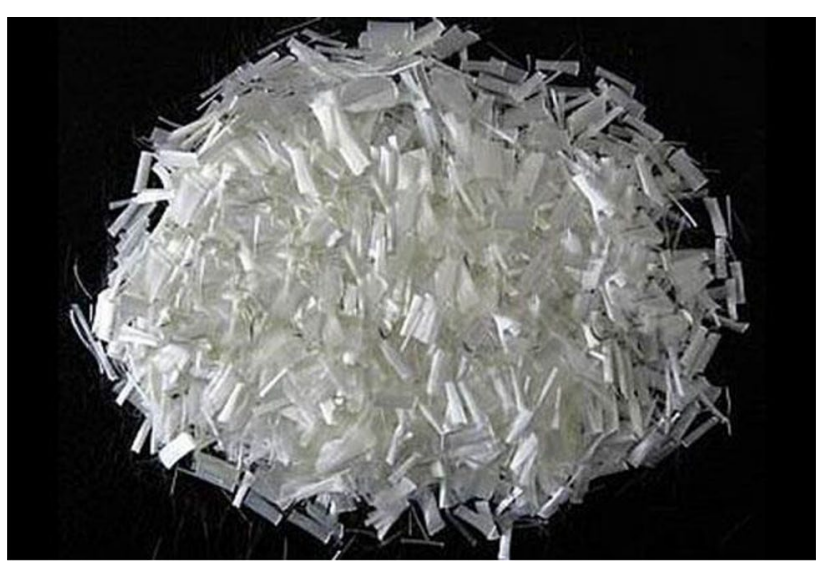

Fig. 3 Glass fibers (12 $\mathrm{mm}$ in length)

Table 3 Physical properties of glass fiber

\begin{tabular}{ll}
\hline Specifications & Value \\
\hline Diameter (mm) & 0.01 \\
Elegance (denier) & 2 \\
Density (g per cubic centimeter) & 2.44 \\
Tensile strength (Mpa) & 2310 \\
Young's modulus (GPa) & 68.9 \\
Melting point $\left({ }^{\circ} \mathrm{C}\right)$ & 705 \\
\hline
\end{tabular}




\subsubsection{Adding glass fiber}

There are two ways for adding the glass fibers to the asphalt mix:

\section{Wet method}

Dry method

In the wet method, the fibers are first mixed with bitumen, and then, the aggregates are added to the mix. The major flaw of this method is the balling of the fibers in

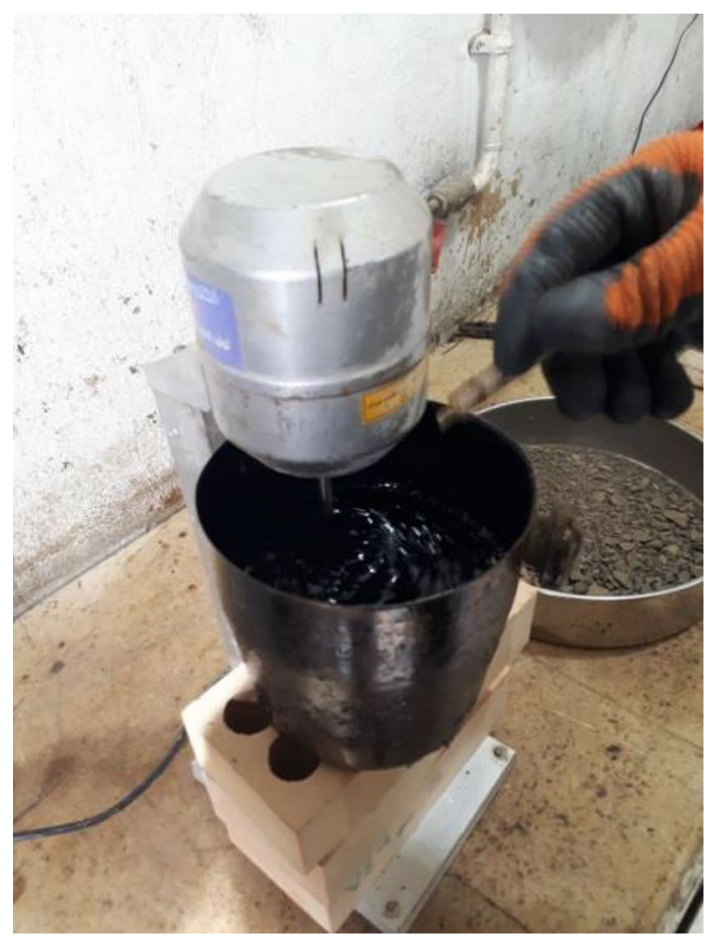

Fig. 4 Admixture of bitumen and EVA polymer the bitumen, which makes the mixing process unfit. In the dry method, the fibers are first added to the aggregates, and then, the bitumen is added, and the asphalt mixture is produced.

The dry method was used to mix the fibers with aggregates. A stable weight percentage of glass fiber was used for all samples, i.e., $3 \%$ weight of mix (with a length of $12 \mathrm{~mm}$ ).

\subsubsection{Laboratory process}

This research studies asphalt mix samples made by pure bitumen and compares them with asphalt mix samples made by modified polymeric bitumen reinforced with glass fiber. The samples are categorized into four groups: additive-free (control) samples, samples made by polymer, samples reinforced with glass fiber, and samples made by EVA polymer and glass fiber.

For simplicity, we use $\mathrm{E}$ to represent samples having EVA polymer and $\mathrm{F}$ for samples having glass fiber. A total of 11 asphalt mixes were carried out for different conditions; three repetitions on samples were performed; Table 4 names the asphalt samples used in this research. It should be mentioned that bitumen percentage of all samples is identical and equal to optimum bitumen content (OBC) [9, $35,36]$. Also, the air void percentage was about $4 \%$.

\section{Testing methods}

\subsection{Marshall test}

In order to determine the unit weight of the asphalt mix, the samples are put in 60 degrees centigrade water for $30 \mathrm{~min}$. Using the Marshall machine, the strength and flow of the mix were immediately tested based on ASTM-D1559

Table 4 Combination percent of EVA additive in bitumen and glass fiber in the aggregates in asphalt mixtures

\begin{tabular}{lll}
\hline The name of combination & Explanations & $\begin{array}{c}\text { Number of } \\
\text { repetitions }\end{array}$ \\
\hline OEOF & Base state & 3 \\
$3 \mathrm{E}$ & $3 \%$ of EVA polymer & 3 \\
$5 \mathrm{E}$ & $5 \%$ of EVA polymer & 3 \\
$7 \mathrm{E}$ & $7 \%$ of EVA polymer & 3 \\
$1 \mathrm{~F}$ & $0.1 \%$ of glass fiber sample by weight $(1200 \mathrm{gr})$ & 3 \\
$2 \mathrm{~F}$ & $0.2 \%$ of glass fiber sample by weight $(1200 \mathrm{gr})$ & 3 \\
$3 \mathrm{~F}$ & $0.3 \%$ of glass fiber sample by weight $(1200 \mathrm{gr})$ & 3 \\
$4 \mathrm{~F}$ & $0.4 \%$ of glass fiber sample by weight $(1200 \mathrm{gr})$ & 3 \\
$3 \mathrm{EF}$ & The combination of 3\% of EVA polymer and optimal percentage of glass fiber \\
$5 \mathrm{EF}$ & The combination of 5\% of EVA polymer and optimal percentage of glass fiber & 3 \\
$7 \mathrm{EF}$ & The combination of 7\% of EVA polymer and optimal percentage of glass fiber & 3 \\
\hline
\end{tabular}


(Fig. 5). The samples in this research were $6.83 \mathrm{~cm}$ in height. A correction coefficient of 0.86 was used to report Marshall Stability. It should be noted that for each sample, 3 identical asphalt mixes were tested, and the final result was reported in the form of a numerical average.

\subsection{Resilient modulus test $\left(M_{R}\right)$}

Since the load applied in the resilient modulus test is small, this test is considered nondestructive. So, the existent samples can be used in other tests. In the ASTM-D4123 standard, the process of determining the resilient modulus of the asphalt mix is expressed by the indirect tensile test. In this research, based on the standard mentioned above, the UTM14 machine is used to determine the resilient modulus; to do the resilient modulus test, first, the samples are put in oven at the desired temperature for $14 \mathrm{~h}$. Then, after the semi-sinusoidal loading, the resilient modulus of the asphalt samples is determined with $1 \mathrm{HZ}$ frequency and a loading period of $0.1 \mathrm{~s}(0.9-\mathrm{s}$ rest). It should be noted that the relationship mentioned in the ASTM D4123 standard is used to determine the resilient modulus by the UTM software. Resilient modulus is a vital variable in mechanical designing approaches for pavement structures.

In this study, the resilient modulus test was done with $1 \mathrm{~Hz}$ frequency and semi-sinusoidal loading at 25 degrees centigrade. The average amount of resilient modulus from 3 tests was determined as the resilient modulus for each sample. The repetitive loading at 25 degrees centigrade was decided to be $15 \%$ of indirect tensile resistance of the mix (the machine has considered it to be $1000 \mathrm{~N}$ ) to maintain the linear viscoelastic behavior. The preloading cycles were selected to be 200 cycles; therefore, to maintain the effects of the production method and compaction in two vertical directions, the resilient modulus test was done for each sample, and the average of the two numbers was selected as the modulus for each sample. It should be noted that the UTM14 was used to determine the resilient modulus of the samples (Fig. 6).

\section{Results and discussion}

\subsection{Marshall test}

\subsubsection{The effect EVA on Marshall Stability of the asphalt mix}

As can be seen in Fig. 7, adding EVA to the asphalt mix changes the Marshall Stability. The changing process is irregular. According to results, adding 3\% of EVA polymer decreases the Marshall Stability, while adding 5\% of EVA increases it. Then, increasing the amount of additives causes a descending process in the Marshall Stability. As a result, compared to the control sample, the stability of the asphalt mix made by this kind of bitumen decreases. On the other hand, a decrease in Marshall Stability in amounts more than $5 \%$ may be the result of the unsuitable compaction of samples after increasing the viscosity of the bitumen modified by EVA polymer. As EVA increases, the viscosity increases, and the temperature required for mixing and compaction increases. So, the stability decreases slightly.

\subsubsection{The effect of glass fiber on the Marshall Stability of the asphalt mix}

In order to create cohesion among different components, the fibers make the asphalt mix more solid and increase its resistance to the load applied. As shown in Fig. 8, up until F3, changes in the Marshall Stability of the asphalt mixes are ascending, and after $\mathrm{F} 3$, the changes are descending.
Fig. 5 Jack and Marshall bathroom

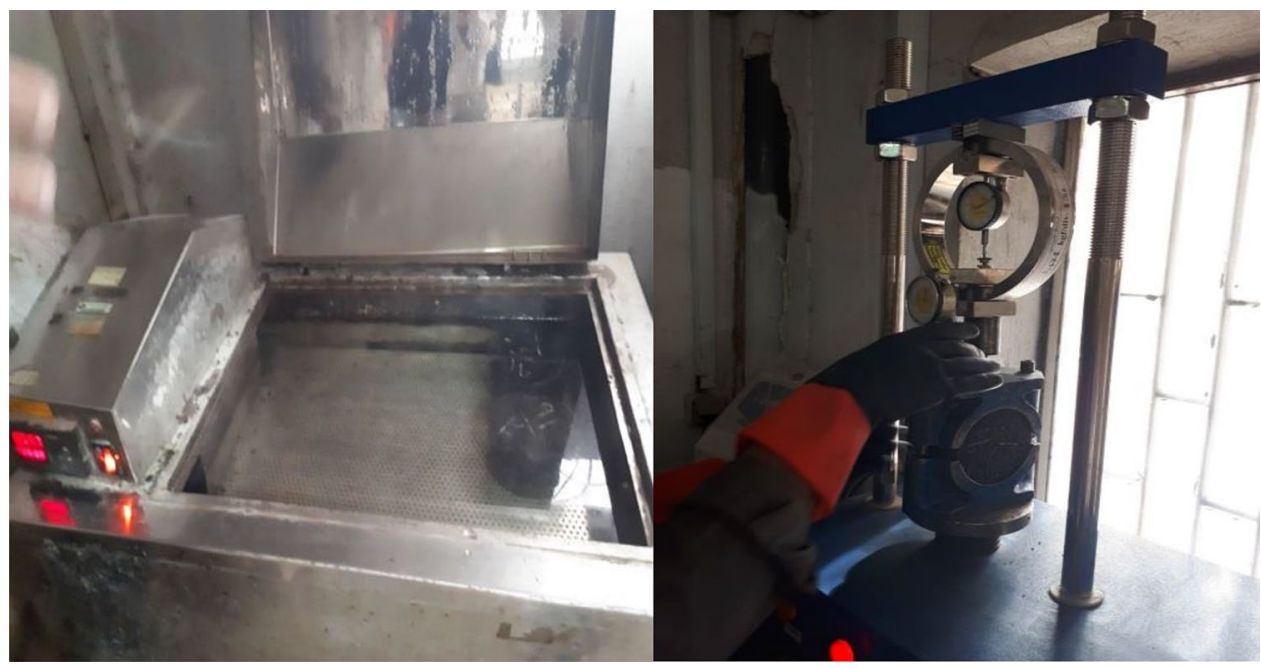




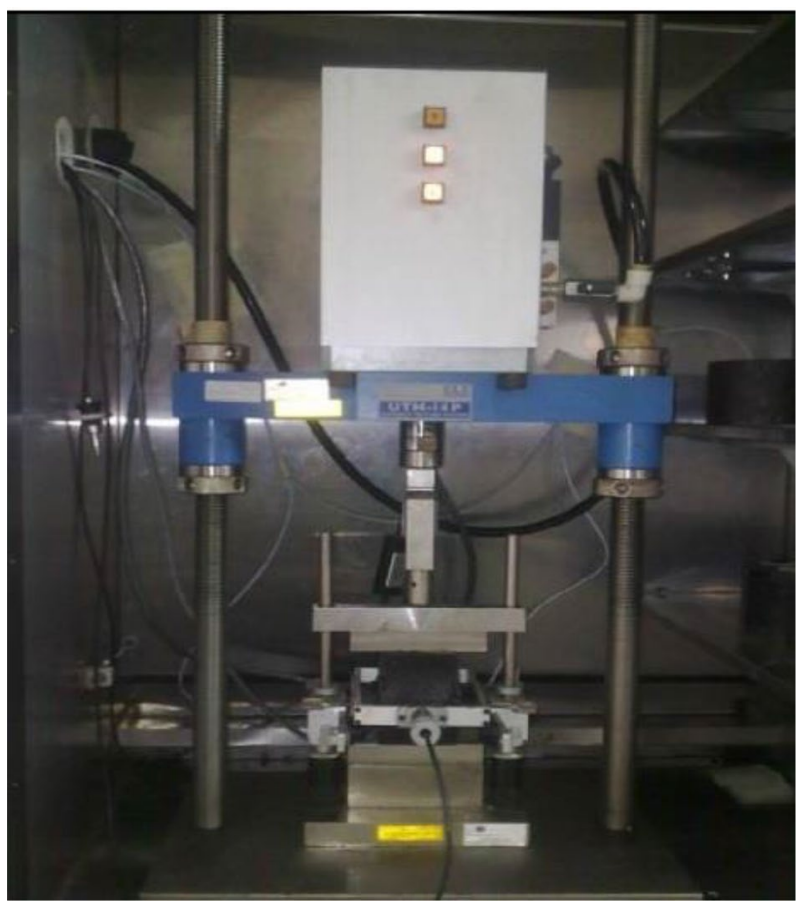

Fig. 6 UTM machine

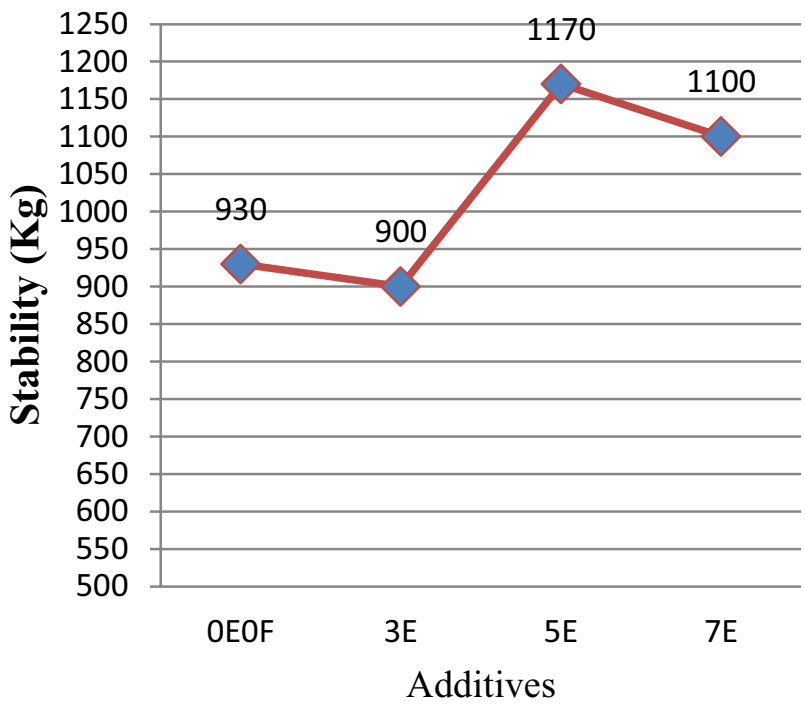

Fig. 7 Marshall Stability of asphalt mixes modified by EVA

As the percentage of fiber in the mixture increases, the friction between the aggregates decreases, and eventually, the Marshall STABILITY decreases. In general, with increasing fiber length, the effect of arming is increased, and finally, bearing of the asphalt mix is increased. However, by increasing the length of fiber to more than $10 \mathrm{~mm}$, the resistance decreases [36].

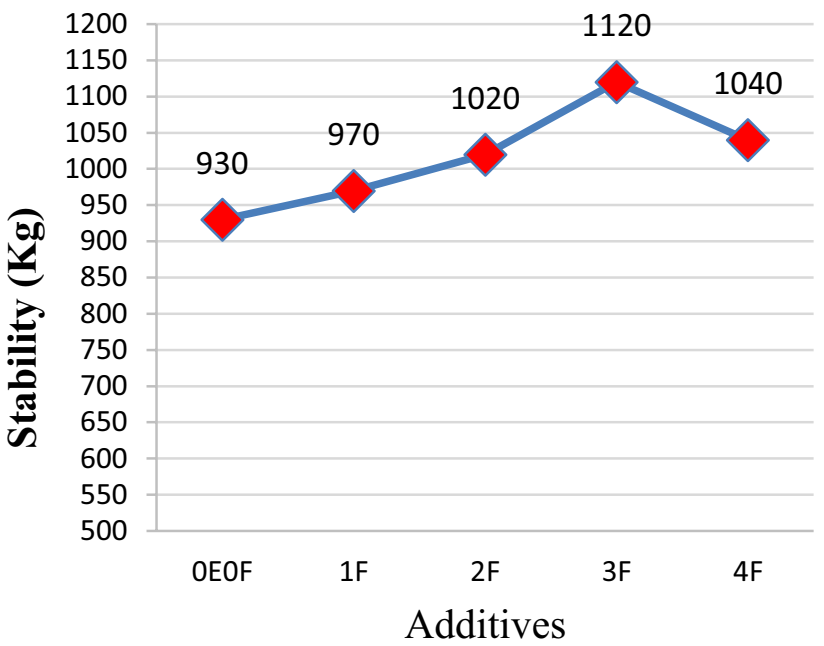

Fig. 8 Marshall Stability of asphalt mixes reinforced with glass fiber

\subsubsection{The simultaneous effect of EVA polymer and glass fiber on the Marshall Stability of the asphalt mix}

Considering the changes in Marshall Stability of the samples in Fig. 8, the highest stability belongs to the mixes made by $0.3 \%$ of glass fiber in $12 \mathrm{~mm}$ length. Thus, this percentage $(0.3 \%-12 \mathrm{~mm})$ was chosen as the optimal amount of glass fiber order to evaluate the two additives conjointly. So, in this paper, in common amounts of the two additives, $F$ represents $0.3 \%$ of glass fiber.

Figure 9 shows the Marshall Stability of the mixes made by different percentages of EVA and $0.3 \%$ of glass fiber in $12 \mathrm{~mm}$ length. When the combination of the additives mentioned above includes up to $3 \%$ of EVA, the Marshall Stability increases. However, increasing EVA to more than 3\% causes the changes in Marshall Stability to follow a descending pattern. It can be said that by increasing the EVA polymer, the viscosity of the bitumen and, consequently, the combination temperature and compaction increase. These changes are small in mixes with $3 \%$ of EVA polymer; therefore, the combination and compaction are much better, and adding the fibers makes a more solid mix. It seems that by increasing the percentage of additives (at constant temperature and constant bitumen content), mixing and compaction operations are not performed well. Therefore, the stability of asphalt mixtures was reduced in $5 \mathrm{EF}$ and $7 \mathrm{EF}$ samples. It should be mentioned that the least amount of Marshall Stability was recorded for $7 \%$ of EVA polymer and $3 \%$ of glass fiber in $12 \mathrm{~mm}$ length, which is still more than the stability of the control mix. 


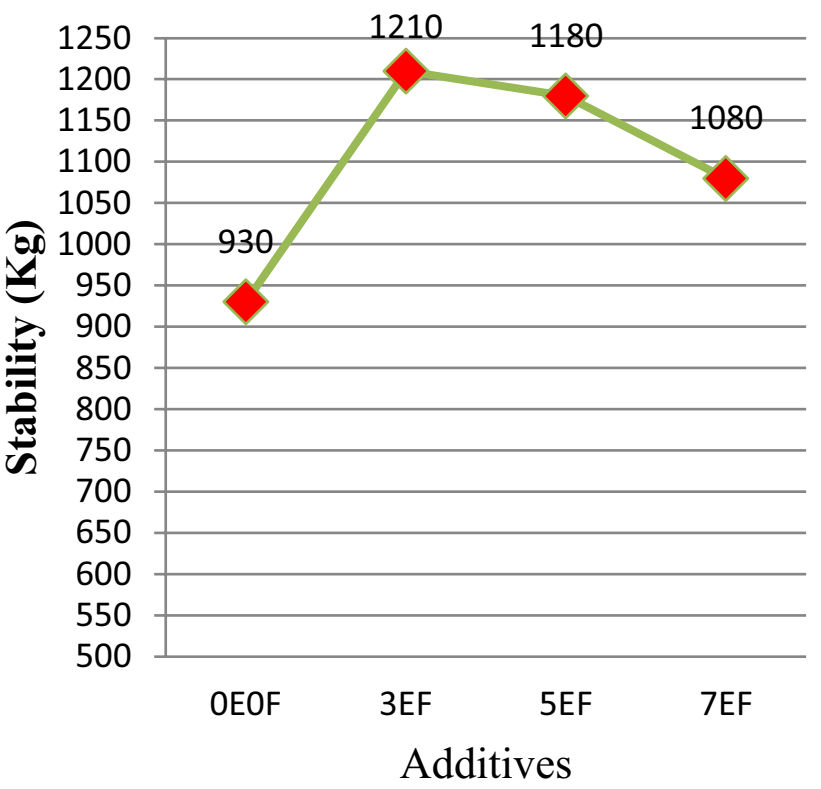

Fig. 9 Marshall Stability of the asphalt mixes modified by glass fiber and EVA

\subsubsection{The effect of EVA on the flow of the asphalt mix}

Adding EVA to the asphalt mix up to $3 \%$ by weight of bitumen increases the flow. Then, increasing the additives up to $5 \%$ causes a decrease in the flow. Moreover, by adding 5-7\% of EVA, the flow increases again. This increase may be related to the chemical reaction of EVA and bitumen. It should be mentioned that in all the mixes, adding EVA polymer causes the flow to be more than the control sample (Fig. 10).

\subsubsection{The effect of glass fiber on the flow of the asphalt mix}

As shown in Fig. 11, increasing the fibers up to a certain point causes a decrease in the flow, and then, after reaching $0.3 \%$, an increase in the flow can be seen. Increasing the fibers causes an increase in the flow because it develops the empty space between the aggregates and decreases the connectivity and friction between them. As a result, internal friction decreases, and the flow increases. It seems that the low percentages of the fibers cause a decrease in the flow. These findings show that adding the glass fibers causes an increase in the resistance to deformation. Compared to the control sample, all the mixes modified by fibers are less flow.

\subsubsection{The simultaneous effect of EVA and glass fiber on the asphalt mix flow}

As it can be observed, the simultaneous increase in EVA and glass fiber causes a decrease in the flow of the asphalt

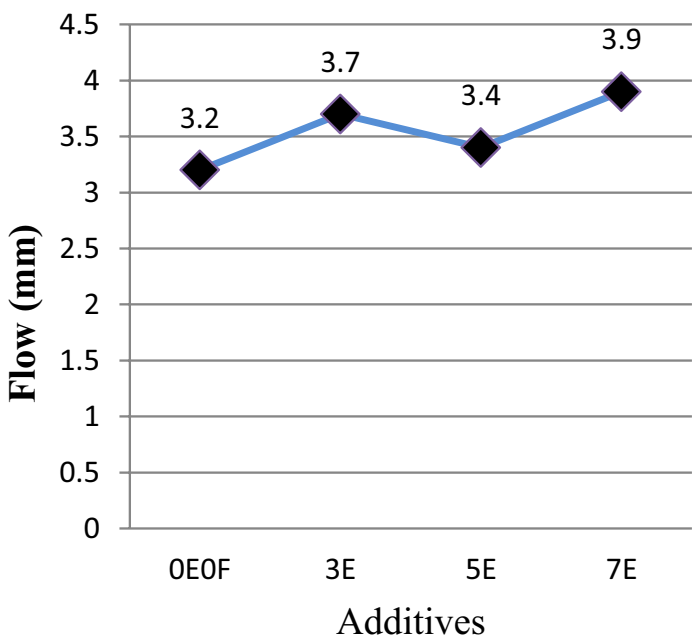

Fig. 10 Marshall flow of the asphalt mixes modified by EVA

mix compared to the control sample modified by $3 \%$ of the polymer. However, increasing EVA in a stable percentage of glass fiber (the amount of flow in the optimum state: $0.3 \%=2.5 \mathrm{~mm}$ ) causes an increase in the flow of the asphalt mixes (Fig. 12). It seems that fibers have a more significant impact on the result.

\subsubsection{The Marshall ratio of asphalt mixes}

Marshall ratio is an empirical parameter that some road administrations in the world, such as UK's TRRL, consider as a criterion for rutting phenomenon [5]. Marshall ratio is defined as the Marshall Stability ratio on the kg scale to the sample's flow on the mm scale. According to the previous studies, the more the Marshall ratio is, the more the asphalt mix resistance to rutting is. Figure 13 shows

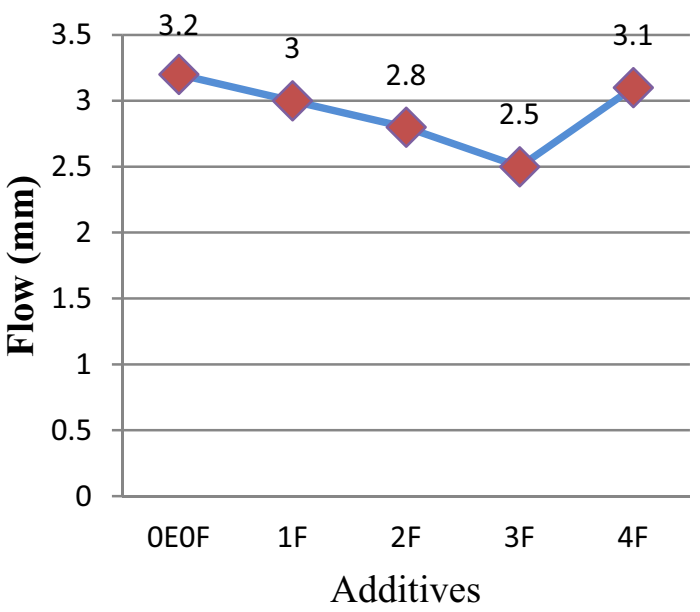

Fig. 11 Marshall flow of asphalt mixes reinforced with glass fiber 


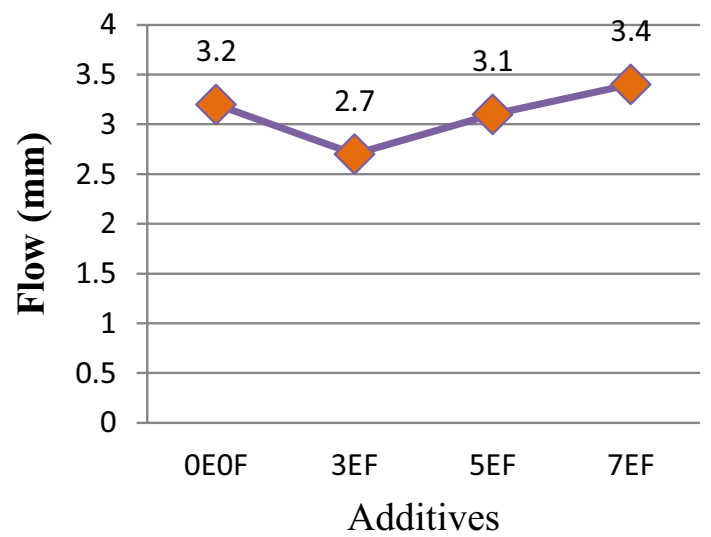

Fig. 12 Marshall flow of the asphalt mixes modified by glass fiber and EVA

the Marshall ratio of all the samples of this research. As can be seen, Marshall ratio changes differently based on different additives. The highest Marshall ratio belongs to the asphalt mix made of $3 \%$ of EVA and $3 \%$ of glass fiber. The lowest Marshall ratio belongs to the asphalt mix made of $3 \%$ of EVA. According to the findings, compared to the EVA polymer, the fibers strongly affect the Marshall ratio of the samples, and the glass fiber has increased the Marshall ratio of samples.

\subsection{Resilient modulus test}

Resilient modulus is a very important engineering feature used to characterize unbound pavement materials [18]. In the following, we discuss the findings of experiments done on the samples studied in this research. For this purpose, the resilient modulus test was performed at a temperature of $25^{\circ} \mathrm{C}$ and $40^{\circ} \mathrm{C}$.

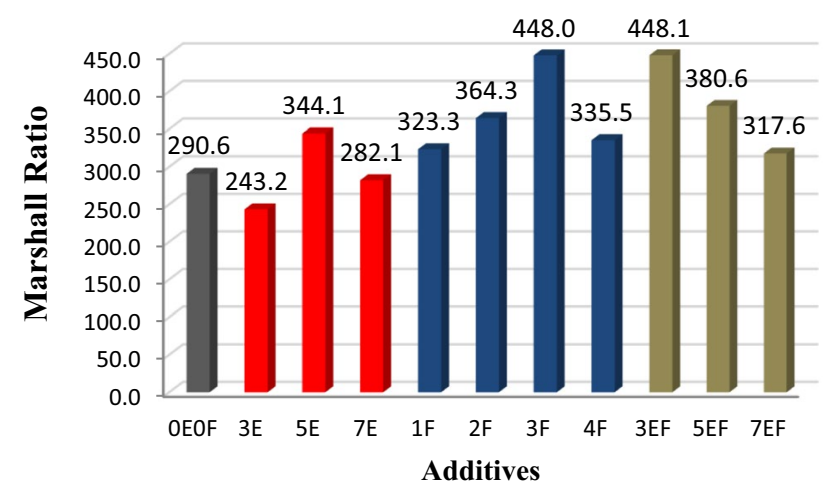

Fig. 13 Marshall ratio of asphalt mixes with different percentages of additives

\subsubsection{Resilient modulus of asphalt mixes modified with EVA polymer}

4.2.1.1 Resilient modulus of asphalt mixes modified with EVA polymer at 25 degrees centigrade Figure 14 shows the changes in the resilient modulus of asphalt mixes at 25 degrees centigrade. As shown in the figure, EVA polymer increases the resilient modulus of the asphalt mixes. Increasing EVA up to 5\%, resilient modulus follows an ascending pattern. For higher amounts, a descending pattern can be seen. The interactions between bitumen and additives in the modified asphalt mixes can strongly influence the behavior of the mix. As the percentage of EVA increases, the interaction between bitumen and the EVA changes, and the polymer phase becomes more dominant. Therefore, with increasing polymer phase in bitumen, the adhesion between bitumen and EVA increases; this increases the locking of the modified bitumen and aggregates, which improves the properties of the mixture. In amounts higher than the optimal percentage, polymer dominates, and it destroys bitumen structure. As a result, the strength and stiffness of the mix decrease [21].

4.2.1.2 Resilient modulus of asphalt mixes modified with EVA polymer at $\mathbf{4 0}$ degrees centigrade As shown in Fig. 15, EVA-containing samples have got a higher resilient modulus than the control sample. By increasing EVA, resilient modulus increases at 40 degrees centigrade. The changes in resilient modulus are almost similar to the findings of the previous part. As the temperature rises $\left(25-40{ }^{\circ} \mathrm{C}\right)$, the asphalt mixture becomes softer, and the effect of EVA on the asphalt mixture increases. Therefore, it seems that at high temperatures, EVA increases the resilient modulus of the asphalt mixture by increasing the viscosity of the bitumen. It seems that the presence of EVA,

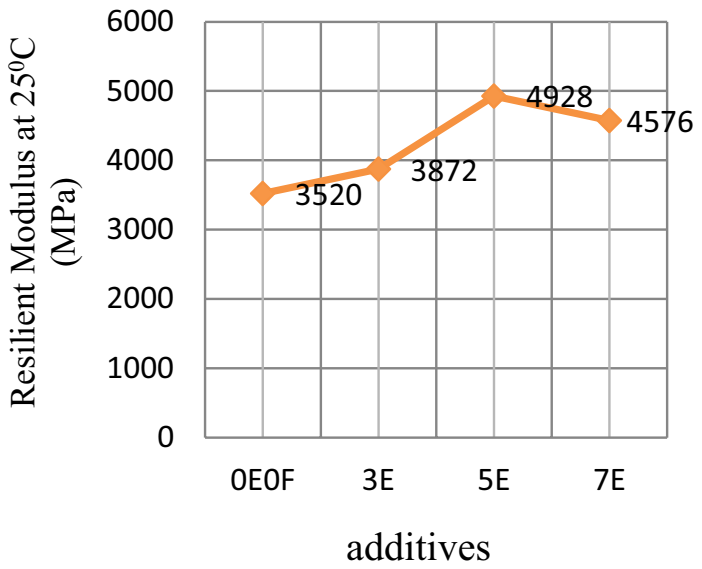

Fig. 14 Resilient modulus of asphalt mixes modified with EVA at 25 degrees centigrade 


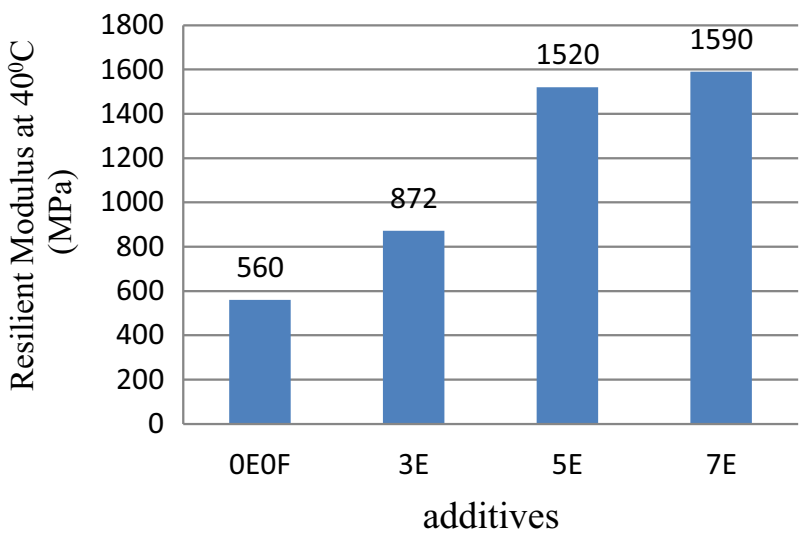

Fig. 15 Results of the resilient modulus on the MPa scale at 40 degrees centigrade for samples containing different EVA percentages

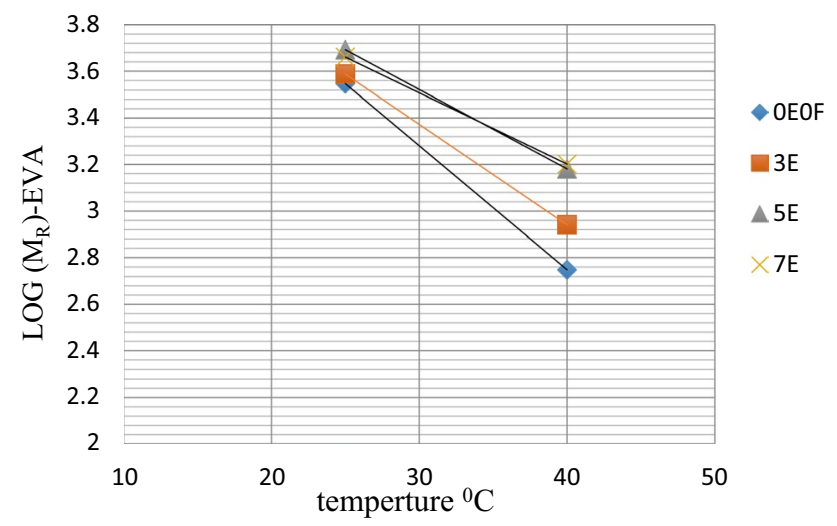

Fig. 16 Resilient modulus changes caused by temperature

due to its properties, improves the mechanical properties of asphalt mixtures.

4.2.1.3 Thermal sensitivity (MR changes caused by the rise in temperature) Generally speaking, the more the diagram slope is, the more the thermal sensitivity is. It can be observed that increasing the EVA polymer, the diagram slope, and thermal sensitivity decrease (Fig. 16).

\subsubsection{Resilient modulus of asphalt mixes reinforced with glass fiber}

4.2.2.1 Resilient modulus of asphalt mixes reinforced with glass fiber at 25 degrees centigrade Based on Fig. 17, the glass fibers make the mix components more solid and increase the resilient modulus. Increasing the glass fiber up to $0.3 \%$, the changes in the resilient modulus are ascending. In higher percentages, a descending pattern can be seen. It is also observed that lower amounts of

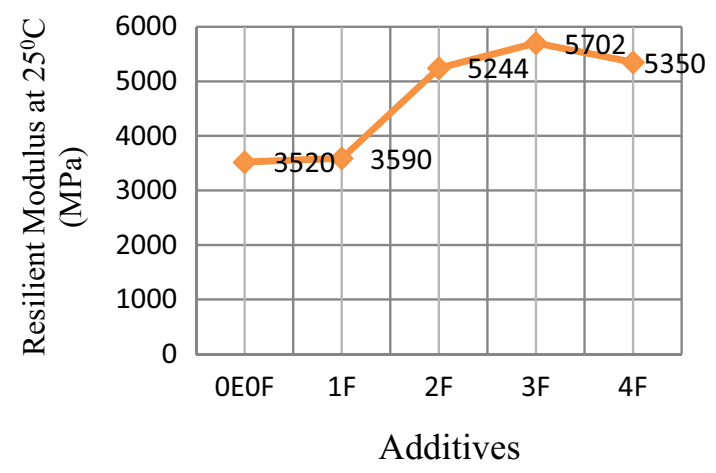

Fig. 17 Resilient modulus of asphalt mixes reinforced with glass fiber at 25 degrees centigrade

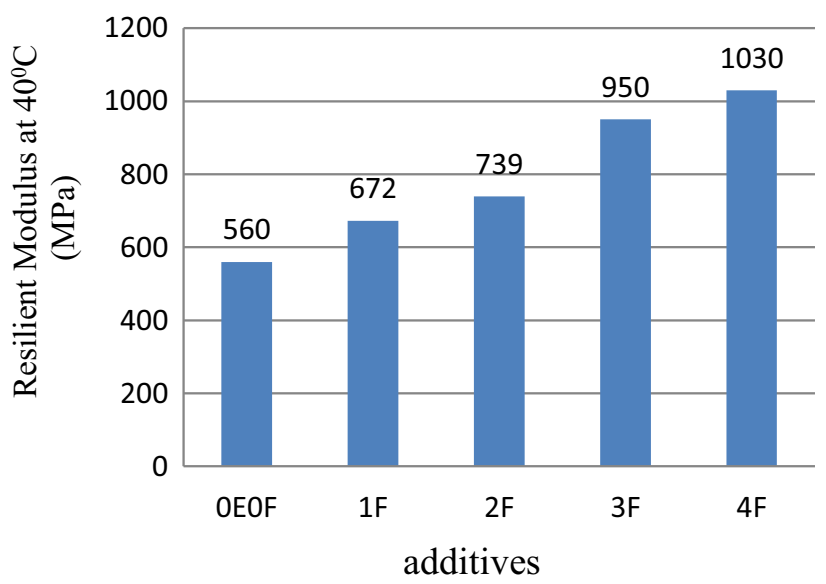

Fig. 18 Results of the resilient modulus on the MPa scale at 40 degrees centigrade for samples containing different percentages of glass fiber in $12 \mathrm{~mm}$ length

glass fiber $(0.1 \%)$ do not have a substantial effect on the asphalt mix. The presence of glass fiber seems to improve the mechanical properties of the asphalt mixture due to its elasticity.

4.2.2.2 Resilient modulus of asphalt mixes reinforced with glass fiber at $\mathbf{4 0}$ degrees centigrade As shown in Fig. 18, samples containing glass fiber have got more resilient modulus than the control samples. Increasing the amount of glass fiber, the resilient modulus increases at 25 degrees centigrade. The changes in resilient modulus are almost similar to the results of the previous part.

4.2.2.3 Thermal sensitivity (MR changes caused by a rise in temperature) As can be seen, adding $0.1 \%$ of glass fiber to the asphalt mix decreases thermal sensitivity, and adding $0.2 \%$ of glass fiber increases it. In higher percentages, thermal sensitivity follows a descending pattern (Fig. 19). 


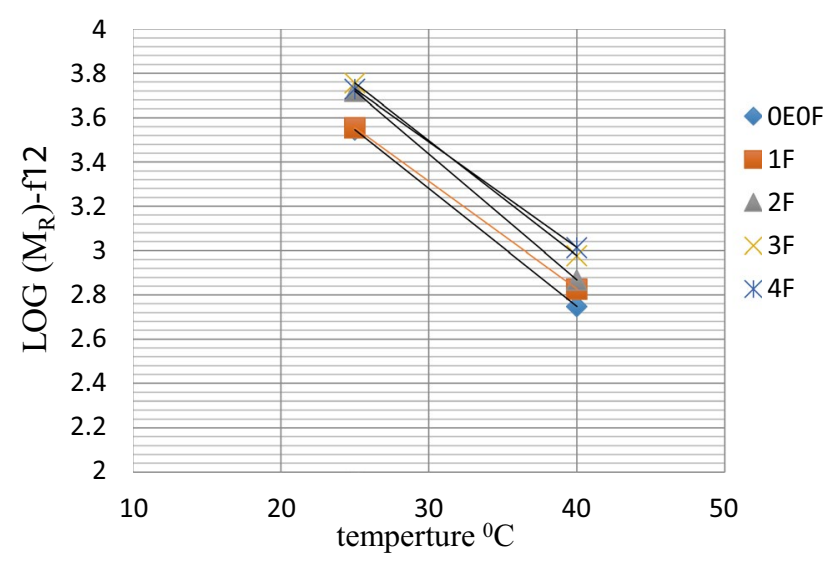

Fig. 19 Resilient modulus changes caused by temperature

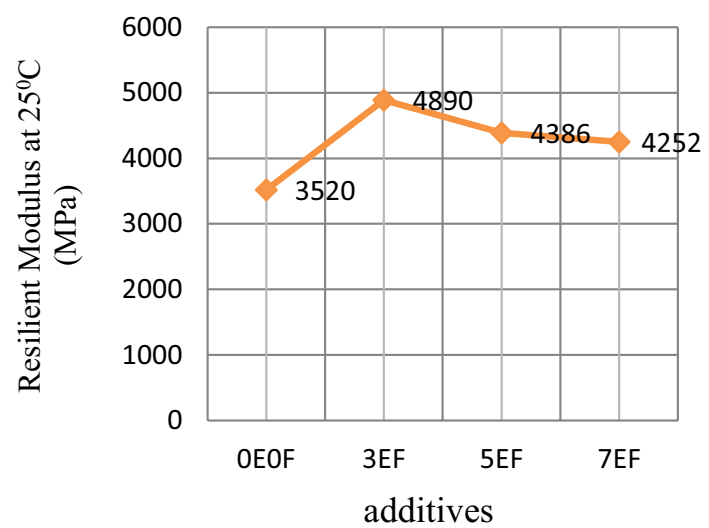

Fig. 20 Resilient modulus of asphalt mixes containing both EVA and glass fiber at 25 degrees centigrade

Generally, the thermal sensitivity of the asphalt mixture is not affected by the glass fiber.

\subsubsection{The resilient modulus of asphalt mixes reinforced with glass fiber and EVA polymer}

4.2.3.1 The resilient modulus of asphalt mixes reinforced with glass fiber and EVA polymer at 25 degrees centigrade As shown in Fig. 20, having a stable percentage of glass fiber $(0.3 \%)$ and increasing the polymer up to $3 \%$, the changes in the resilient modulus of the samples follow an ascending pattern. In higher percentages of polymer, a descending pattern can be seen. However, it is still more than the resilient modulus of the mix in the control state.

4.2.3.2 The resilient modulus of asphalt mixes reinforced with glass fiber and EVA polymer at $\mathbf{4 0}$ degrees centigrade As shown in Fig. 21, adding two kinds of additives to the mix, the resilient modulus increases at 40 degrees

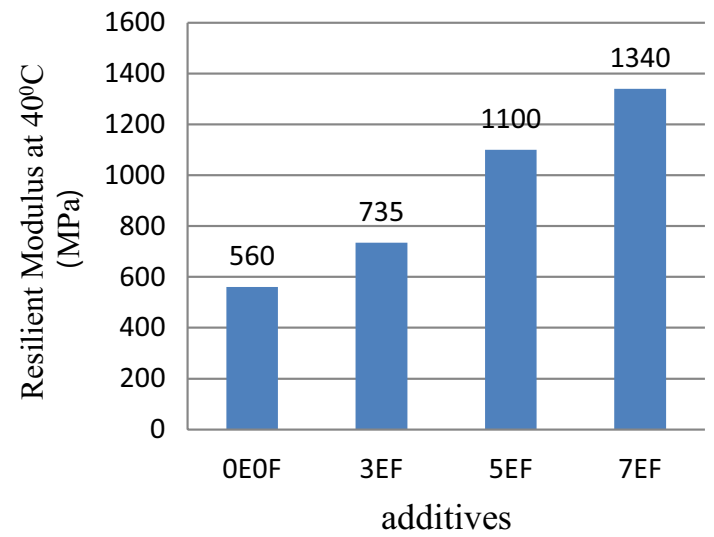

Fig. 21 Results of the resilient modulus on the MPa scale at 40 degrees centigrade for samples containing different EVA percentages and $3 \%$ of glass fiber in $12 \mathrm{~mm}$ length

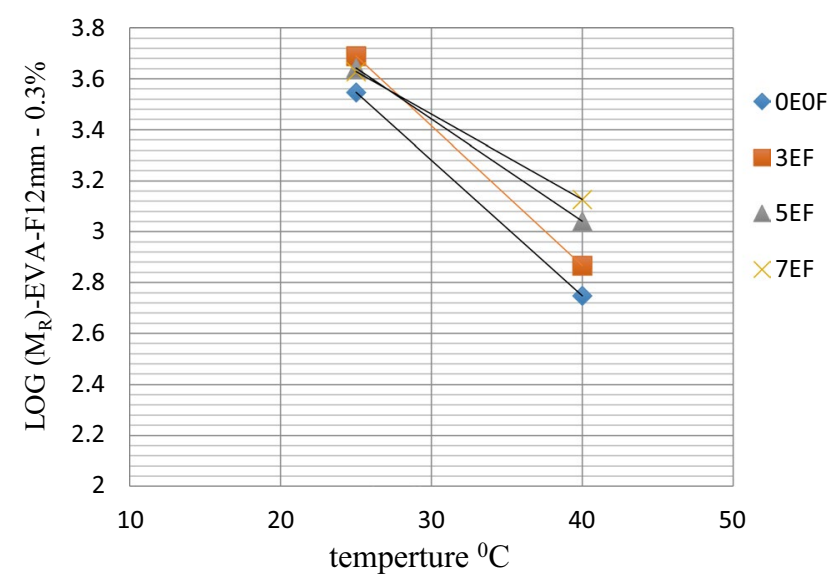

Fig. 22 Resilient modulus changes caused by temperature

centigrade. The reason is related to the behavior of EVA in asphalt. As mentioned, at high temperatures, EVA increases the viscosity of bitumen, which increases the resilient modulus of the asphalt mixture in an ascending pattern.

4.2.3.3 Thermal sensitivity (MR changes caused by a rise in temperature) Considering the results mentioned above, as shown in Fig. 22, adding 3\% of polymer to the asphalt mix containing $3 \%$ of glass fiber increases thermal sensitivity. In higher percentages of polymer, thermal sensitivity follows a descending pattern. (Compared to the previous two modes, it is tangible.)

In general, it seems that the presence of EVA in the mix improves the characteristics of the asphalt mixture. 


\section{Conclusion}

- This research evaluates performance changes in the asphalt mix used in a surface layer of asphalt pavements. These changes are done by adding two kinds of additives, including the common industrial arming additives (glass fibers) and useful polymers (EVA). Based on laboratory tests, the mechanical performance of asphalt mixes was studied. The weight of the bitumen was stable, and the amount of each additive was changed. The simultaneous effect of both additives was also investigated. After comparing the results of the tests, the following findings were reported:

- The pattern of changes in the Marshall Stability is not a clear and disciplined one. Increasing 3-5\% of EVA polymer increases the Marshall Stability due to the increased viscosity of the bitumen. The highest Marshall Stability belonged to the asphalt mix containing $5 \%$ of EVA, which is equal to $1170 \mathrm{~kg}$.

- Glass fiber in $12 \mathrm{~mm}$ length increases the Marshall Stability of the asphalt mix due to the arming of the asphalt mix. By increasing 3\% of glass fiber, the Marshall Stability changes from $930 \mathrm{~g}$ to $1120 \mathrm{~kg}$.

- Adding 3\% of EVA to the asphalt mix reinforced with $0.3 \%$ of glass fiber caused an increase in the Marshall Stability compared to the control sample $(1210 \mathrm{~kg})$. However, increasing the polymer and keeping the glass fiber in a stable point caused a decrease in the Marshall Stability so that by adding $7 \%$ of EVA polymer, the Marshall Stability reached $1080 \mathrm{~kg}$.

- According to the results, the highest Marshall Stability belongs to the sample containing 3\% of EVA and 3\% of glass fiber, which is equal to $1210 \mathrm{~kg}$. The reason is related to the increased viscosity of bitumen and the arming of the asphalt mix.

- Increasing the polymer, the flow of the samples containing EVA polymer has got an unclear pattern. Adding $3 \%$ of EVA polymer increases the flow $(3.7 \mathrm{~mm})$, and adding $5 \%$ of EVA polymer decreases it $(3.4 \mathrm{~mm}$ ). Increasing EVA up to $7 \%$ causes an increase in the flow $(3.9 \mathrm{~mm})$.

- Increasing the fibers up to $3 \%$ decreases the flow of the asphalt mix $(2.5 \mathrm{~mm})$, but higher amounts of the fibers increase the flow $(3.1 \mathrm{~mm})$.

- In asphalt mixes containing both additives, increasing EVA (while glass fiber is stable) causes a decrease in the flow $(2.5 \mathrm{~mm})$. In higher amounts, the flow increases so that increasing EVA up to $7 \%$ causes the flow to reach $3.4 \mathrm{~mm}$.

- The highest Marshall flow belongs to the mix containing $7 \%$ of EVA (3.4 mm), and the lowest Marshall flow belongs to the sample reinforced with $0.3 \%$ of glass fiber $(2.5 \mathrm{~mm})$.

- Generally speaking, the simultaneous combination of both EVA and glass fiber causes the Marshall ratio to increase compared to the related combinations (combining the two additives causes the resistance to rutting to increase more compared to other mixes).

- Marshall ratio in mixes made by glass fiber is higher than mixes made by EVA (glass fiber is more influential than EVA in increasing resistance to rutting).

- The highest Marshall ratio belongs to the sample 3EF (asphalt mix containing 3\% of EVA and 3\% of glass fiber), which is equal to 448.1 ( $\mathrm{kg} / \mathrm{mm})$, and the lowest Marshall ratio belongs to the sample 3E (asphalt mix containing $3 \%$ of EVA).

- Due to the dominance of the polymer phase and the increase in mechanical and dynamic properties, by increasing the EVA polymer, the resilient modulus increases compared to the control sample so that increasing EVA up to 5\%, the resilient modulus changes from 3520 to $4928 \mathrm{MPa}$.

- Using glass fibers in amounts of less than $2 \%$ does not influence the resilient modulus of asphalt mixes. However, increasing the glass fiber makes the difference in resilient modulus considerable so that a $3 \%$ increase in glass fiber changes the resilient modulus of asphalt mixes from 3520 to $5702 \mathrm{MPa}$.

- In mixes containing both additives, increasing EVA polymer up to $3 \%$ causes an increase in the resilient modulus (4890 MPa). However, in higher percentages of EVA, when the fiber is stable, the resilient modulus decreases.

- Generally speaking, the rise in temperature decreases the viscosity of the bitumen and leads to a decrease in the resilient modulus of asphalt mixes, adding EVA to the bitumen, the viscosity, and resilient modulus increase. By increasing the stiffness of the bitumen, the glass fiber plays a vital role in increasing the resilient modulus. The important point to mention is that the polymer has got a more significant influence than fiber. Having a stable percentage of glass fiber, and changing the polymer percentage, an increase in the resilient modulus can be seen. However, the polymer still plays a more important role on its own.

- The highest resilient modulus belongs to the sample containing 3\% of glass fiber, and the lowest resilient modulus belongs to the control sample.

- Considering the Marshall Stability, 3EF was selected as the most optimal asphalt mix. 


\section{Compliance with ethical standards}

Conflict of interest The authors declare that they have no conflict of interest.

\section{References}

1. Abdi A, Zarei M, Mahdinazar M, Akbarinia F (2020) Economic analysis based on the unit weight of hot mix asphalt. Eng Solid Mech 8(4):1-10

2. Abtahi SM, Sheikhzadeh M, Hejazi SM (2010) Fiber-reinforced asphalt-concrete-a review. Constr Build Mater 24(6):871-877

3. Al-Hadidy Al, Tan YQ (2010) The effect of SBS on asphalt and SMA mixture properties. J Mater Civ Eng 1(1):156

4. Alhamali DI, Wu J, Liu Q, Hassan NA, Yusoff NIM, Ali SIA (2016) Physical and rheological characteristics of polymer modified bitumen with nanosilica particles. Arab J Sci Eng 41(4):1521-1530

5. Ameri M, Mansourian A, Ashani SS, Yadollahi G (2011) Technical study on the Iranian Gilsonite as an additive for modification of asphalt binders used in pavement construction. Constr Build Mater 25(3):1379-1387

6. Bai T, Hu ZA, Hu X, Liu Y, Fuentes L, Walubita LF (2019) Rejuvenation of short-term aged Asphalt-binder using waste engine oil. Can J Civ Eng. https://doi.org/10.1139/cjce-2019-0268

7. Barati M, Zarei M, Zahedi M (2015) Compare the effect of carbon nanotubes and glass powder on Marshall Stability and flow of asphalt mixtures. In: Conference: 3rd international congress on civil engineering, architecture and urban development, pp 39-47

8. Behnood A, Gharehveran MM (2019) Morphology, rheology, and physical properties of polymer-modified asphalt binders. Eur Polym J 112:766-791

9. Guo Q, Li L, Cheng Y, Jiao Y, Xu C (2015) Laboratory evaluation on performance of diatomite and glass fiber compound modified asphalt mixture. Mater Des 1980-2015(66):51-59

10. Hafeez I, Kamal MA (2014) Creep compliance: a parameter to predict rut performance of asphalt binders and mixtures. Arab J Sci Eng 39(8):5971-5978

11. Hu X, Fan S, Li X, Pan P, Fuentes L, Walubita LF (2020) Exploring the feasibility of using reclaimed paper-based asphalt felt waste as a modifier in asphalt-binders. Constr Build Mater 234:117379

12. Hussein IA, Iqbal MH, Al-Abdul-Wahhab $\mathrm{HI}$ (2005) Influence of $\mathrm{M}$ w of LDPE and vinyl acetate content of EVA on the rheology of polymer modified asphalt. Rheol Acta 45(1):92-104

13. Khattak M, Baladi G (2001) Fatigue and permanent deformation models for polymer-modified asphalt mixtures. Transp Res Rec J Transp Res Board 1767:135-145

14. Kumar P, Mehndiratta HC, Singh KL (2010) Comparative study of rheological behavior of modified binders for high-temperature areas. J Mater Civ Eng 22(10):978-984

15. Mahrez A, Karim M, Katman H (2003) Prospect of using glass fiber reinforced bituminous mixes. J East Asia Soc Transp Stud 5:794-807

16. Mirbaha B, Abdi A, Zarei M, Zarei A, Akbarinia F (2017) Experimental determination of the optimum percentage of asphalt mixtures reinforced with nano-carbon black and polyester fiber industries. Eng Solid Mech 5(4):285-292

17. Mohamed N, Maharaj R, Ramlochan D (2017) Rutting and fatigue cracking susceptibility of polystyrene modified asphalt. Am J Appl Sci 14(5):583-591
18. Roustaei M, Eslami A, Ghazavi M (2015) Effects of freeze-thaw cycles on a fiber reinforced fine grained soil in relation to geotechnical parameters. Cold Reg Sci Technol 120:127-137

19. Sallam HEDM, Mubaraki M, Yusoff NIM (2014) Application of the maximum undamaged defect size (d max) concept in fiber-reinforced concrete pavements. Arab J Sci Eng 39(12):8499-8506

20. Saoula S, Mokhtar KA, Haddadi S, Ghorbel E (2009) Improvement of the performances of modified bituminous concrete with EVA and EVA-waste. Phys Procedia 2(3):1319-1326

21. Sengoz B, Isikyakar G (2008) Evaluation of the properties and microstructure of SBS and EVA polymer modified bitumen. Constr Build Mater 22(9):1897-1905

22. Serin S, Morova N, Saltan M, Terzi S (2012) Investigation of usability of steel fibers in asphalt concrete mixtures. Constr Build Mater 36:238-244

23. Wekumbura C, Stastna J, Zanzotto L (2005) Stress growth coefficient in polymer modified asphalt. Mater Struct 38(8):755-760

24. Xu O, Xiao F, Han S, Amirkhanian SN, Wang Z (2016) High temperature rheological properties of crumb rubber modified asphalt binders with various modifiers. Constr Build Mater 112:49-58

25. Zahedi M, Zarei M (2016) Studying the simultaneous effect of black Nanocarbon and Polyester fibers with high stability on mechanical properties of asphalt mixture

26. Zahedi M, Rahmani Z, Zarei M (2015) Compare the effect of rubber powder and industry carbon fiber on Marshall Stability and flow of asphalt mixtures. In: Conference: 3rd international congress on civil engineering, architecture and urban development, pp 1-10

27. Zahedi M, Barati M, Zarei M (2017) Evaluation the effect of carbon nanotube on the rheological and mechanical properties of bitumen and Hot Mix Asphalt (HMA). Electron J Struct Eng 17(1):76-84

28. Zahedi M, Barati M, Zarei M (2017) Studying the technical effect of carbon nanotube on asphalt mixture with solid granulation. J Civ Eng Struct 1(1):2017

29. Zahedi M, Zarei M, Manesh HA, Kalam A, Ghadiri M (2017) Technical-economic studies about polyester fibers with high strength on asphalt mixtures with solid granulation. J Civ Eng Urban 7(2):30-35

30. Zahedi M, Zarei A, Zarei M, Janmohammadi O (2020) Experimental determination of the optimum percentage of asphalt mixtures reinforced with Lignin. SN Appl Sci 2(2):258

31. Zanzotto L, Stastna J, Vacin O (2000) Thermomechanical properties of several polymer modified asphalts. Appl Rheol 10(4):185-191

32. Zarei M, Zahedi M (2016) Effect of nano-carbon black on the mechanical properties of asphalt mixtures. J Fundam Appl Sci 8(3S):2996-3008

33. Zarei M, Barati M, Zahedi M (2015) Compare the effect of nano carbon black and industry polyester fiber on Marshall Stability and flow of asphalt mixtures. In: Conference: 3rd international congress on civil engineering, architecture and urban development, pp 20-28

34. Zarei M, Zarei A, Zahedi M (2017) Comparison of the optimum percentage of asphalt mixture reinforced with nano-carbon black and polyester fiber with high strength. J Civ Eng Struct 1(1):13-29

35. Zarei A, Zarei M, Janmohammadi O (2019) Evaluation of the effect of lignin and glass fiber on the technical properties of asphalt mixtures. Arab J Sci Eng 44(5):4085-4094

36. Zarei M, Akbarinia F, Rahmani Z, Zahedi M, Zarei A (2020) Economical and technical study on the effect of carbon fiber with high strength on hot mix asphalt (HMA). Electron J Struct Eng $20(1): 1-6$ 
37. Zarei M, Mirbaha B, Akbarinia F, Rahmani Z, Zahedi M, Zarei A (2020) Application of concordance analysis method (CA) for optimal selection of asphalt mixtures reinforced with rubber powder and carbon fiber. Electron J Struct Eng 20(1):53-62

38. Zarei M, Rahmani Z, Zahedi M, Nasrollahi M (2020) Technical, economic, and environmental investigation of the effects of rubber powder additive on asphalt mixtures. J Transp Eng Part B Pavements 146(1):04019039

39. Zhang J, Faruk AN, Karki P, Holleran I, Hu X, Walubita LF (2016) Relating asphalt binder elastic recovery properties to HMA cracking and fracture properties. Constr Build Mater 121:236-245

40. Zhang J, Simate GS, Hu X, Souliman M, Walubita LF (2017) Impact of recycled asphalt materials on asphalt binder properties and rutting and cracking performance of plant-produced mixtures. Constr Build Mater 155:654-663
41. Ziari H, Moniri A (2019) Laboratory evaluation of the effect of synthetic Polyolefin-glass fibers on performance properties of hot mix asphalt. Constr Build Mater 213:459-468

42. Ziari H, Aliha MRM, Moniri A, Saghafi Y (2020) Crack resistance of hot mix asphalt containing different percentages of reclaimed asphalt pavement and glass fiber. Constr Build Mater 230:117015

Publisher's Note Springer Nature remains neutral with regard to jurisdictional claims in published maps and institutional affiliations. 